\title{
Development and Implementation of an Integrated Approach to Improving the Operating Cycle and Design of an Energy-Efficient Forced Diesel Engine
}

\author{
K.V. Gavrilov, V.G. Kamaltdinov, N.A. Khozeniuk, E.A. Lazarev \\ and Y.V. Rozhdestvensky
}

\begin{abstract}
The methods and means of improving the operating cycle and design of forced diesel, its fuel efficiency, and the limitation of the thermomechanical loading were considered.
\end{abstract}

Keywords Specific power - Mixture formation - Fuel injection

Combustion procedure parameters · Fuel efficiency $\cdot$ Diesel design elements

\section{Introduction}

The aim of this study is to increase the competitiveness of possible by intensification of scientific research and finding of new technical solutions for improving characteristics of a diesel.

This fully applies to the developed six-cylinder V-shaped diesel engine, with a cylinder diameter of $150 \mathrm{~mm}$ and a piston stroke of $160 \mathrm{~mm}$ (further diesel), with

K.V. Gavrilov ( $₫)$ V V.G. Kamaltdinov · N.A. Khozeniuk · E.A. Lazarev ·

Y.V. Rozhdestvensky

South Ural State University, Chelyabinsk, Russia

e-mail: gavrilovkv@susu.ru

V.G. Kamaltdinov

e-mail: kamaltdinovvg@ susu.ru

N.A. Khozeniuk

e-mail: khozeniukna@susu.ru

E.A. Lazarev

e-mail: lazarevea@susu.ru

Y.V. Rozhdestvensky

e-mail: 79080716674@yandex.ru

(C) The Author(s) 2018 
turbocharging and intercooling, intended for application in ground transportation vehicles.

Earlier exploratory research into advanced models identified a number of problems, the most important of which require an integrated approach to further improve the operating cycle $[9$, p. $2 ; 1$, p. $2 ; 8$, pp. 3-15] and design using a mathematical simulation of the main processes in the inside-cylinder space, in the gas path components, the hydrodynamic phenomena in the fuel supply, and the cooling and lubrication systems of diesel.

An integrated approach is based on the following key assumptions:

- common design, structural, and functional technical solutions for creating a forced modification diesel;

- the availability of technical solutions for computational and theoretical control with subsequent adjustment based on the results of tests of a diesel engine;

- compliance with the requirements of the unification of technical solutions design, low metal content, adaptability in production, and economic feasibility;

- the use of mechanisms and systems of the new generation of structural and operational materials to provide design improvement;

- management of the energy-efficient diesel engine by using modern software and computing complexes;

- including a modern microprocessor element base in the structure of control of the executive power and hydromechanical high-speed devices.

The aim of the study is to develop technical solutions to production based on the Russian components of an energy-efficient forced diesel and a specific capacity of at least $35 \mathrm{~kW} / 1$ for ground transport vehicles.

To achieve these goals, the following problems need to be solved.

1. Adaptation and development of existing and new mathematical models, methods of calculation and technical solutions for the elements of forced diesel engines, including

- improving the operating cycle of diesel;

- providing the required thermodynamic state of the gas environment and the conditions of heat and gas exchange in the inside-cylinder space in the basic processes of the operating cycle;

- providing high turbine supercharging with intercooling;

- intensification of the process of fuel injection with electronic control,

- improvement of inside-cylinder configuration space of the combustion chamber and the gas distribution phases;

- evaluation and improvement of the strength characteristics of the piston, connecting rod, crankshaft, and crankcase of a diesel engine with a high maximum pressure of gas in the cylinder;

- determination of tribological characteristics to enhance the bearing capacity of the crank and turbocharger rotor bearings and the performance of the "piston-cylinder liner" system; 
- evaluation and improvement of the strength characteristics of elements of the fuel injector for high-pressure injection.

2. Experimental evaluation of the main technical solutions for improving the systems and diesel units.

3. Creating a prototype of energy-efficient forced diesel with domestic component parts.

4. Bench testing of the developed prototype of the diesel engine.

\section{Literature Review}

The basis of the operating cycle of a diesel with direct injection is enough to put into practice widely approved diesel engine volumetric mixture formation and combustion method, implemented in the undivided combustion chamber, located at the bottom of the piston.

The geometric compression ratios are $13.5 \ldots 14$ units. It is necessary to choose the amount of compression performed on the basis of compromise and due to the need to limit the maximum pressure of the gas in the cylinder and ensure a reliable start-up at low temperatures.

The piston of a forced diesel is bimetallic with oil gallery cooling and a special profile of the skirt. The complex design of the piston is due to the high thermomechanical loading of elements of inside-cylinder space [12, p. 798]. The undivided combustion chamber has a small heat-sensitive surface, which together with a small whirlwind ratio causes a reduction in the heat transfer to the piston and cooling system.

The individual cylinder heads include four valves, the combined inlet and outlet channels with a minimum of hydraulic losses. Liquid cooling cavities in the heads require an individual unit separate from the coolant supply.

The fuel injection equipment includes a common rail accumulating system with electronically controlled fuel injection. The inclined fuel nozzle with a central location and indoor spraying has eight to ten sprayer holes [7, p. 4].

Diesel has a high turbocharged deep intercooling. According to the analysis of flow and working characteristics, we selected a diesel engine with a turbocharger with a one-stage compressor.

Particular attention is paid to improving the efficiency of mixing and complete fuel burn, taking into account the limitations imposed by the thermomechanical stressed parts [12, p. 798]. To achieve the specific power of diesel at least $35^{-2} \mathrm{~kW} / 1$ is necessary to solve the following problems:

- providing charge air options, guaranteeing the mixture with an air-fuel ratio of not less than $1.8 \ldots 2.0$;

- intensification of injection and uniform distribution of fuel in the combustion chamber to achieve the best homogeneity of the mixture; 
- providing timely and complete combustion of fuel with the least possible duration to increase the efficiency of the combustion process.

\section{Methods}

The objectives of improving the operating cycle of diesel were solved using well-known and new methods:

- intensification injection and uniform distribution of fuel in the combustion chamber was achieved using a fuel supply apparatus with a high-pressure injection $(160 \ldots 200 \mathrm{MPa})$ and an optimum number of holes in the sprayer [7, p. 4];

- ensuring timely and complete combustion of fuel with the least possible duration was achieved in the implementation of the above-mentioned methods, combined with increased use of air charge in the combustion chamber and electronically controlled fuel injection;

- reduction of thermal and mechanical loading of components and parts of inside-cylinder space of a diesel engine was achieved by the thermal emission intensity in the initial stage of the combustion process and minimizing the thermal losses;

- cylinder group reliability is achieved by using composite bimetallic pistons with a special profiling forming the skirt undivided combustion chamber;

- the required intensity of heat transfer and heat exchange in the cooling system of regulation is achieved by a dual feed of the coolant in the cylinder head and block.

Increased efficiency of the turbocharger in the diesel is provided by using a single-stage high-pressure compressor with a two-level vane diffuser and the turbine vane nozzle assembly is completed with a turbocharger with a small rotor inertia and short gas path system. As an intermediate charge, air coolers use airliquid heat exchangers with minimal hydraulic resistances for air and fluid paths.

The use in a diesel fuel supply accumulator-type apparatus with high-pressure injection (160...200 MPa) and an optimum number (till 10) sprayer atomizer holes reduced the duration of fuel injection to $1.5 \mathrm{~ms}$ at a sufficiently uniform distribution of fuel in the combustion chamber [7, p. 4]. This agrees with the results of other authors [2, p. 302-303; 11, p. 192].

Use of the cylinder heads of the two inlet channels with profiled boundary contours and minimal flow resistance on the operating speed of the engine provided increased efficiency in filling the cylinder with a fresh charge of up to 0.95 . At the same time, we considered the dimensions (depth, the maximum diameter of the piston head profile) of the undivided combustion chamber in the piston and the specific recommendations of the leading manufacturers of diesel engines for the relevant cylinder diameter, and the location and inclination of the fuel injector in the cylinder head.

Electronic fuel injection control allowed a biphasic injection fuel injection advance angle adjustment depending on the rotational speed of the crankshaft of a diesel engine and the load. As a result, the maximum pressure and the speed of its 
rise in the cylinder and the combustion temperature were reduced. This effect reduces the heat transfer from the gases to the surrounding elements of inside-cylinder space and temperature level of details, the stress in the dangerous area, loads on the main and connecting rod bearings, and diesel vibroacoustic activity. Reduced heat loss also contributes to increasing the excess air ratio.

\section{Theoretical and Experimental Evaluation of the Parameters of the Operating Cycle and Characteristics of the Diesel}

At the initial stage of creating a diesel engine (the design stage), using computational studies we established indicators of the operating cycle for expected characteristics of the fuel burn. For these purposes, we used the method of synthesis of the operating cycle [5, pp. 874-875; 6, pp. 489-492], which was developed in South Ural State University.

An indicator diagram of the pressure $\mathrm{P}$ and the temperature $\mathrm{T}$ of gases is shown in Fig. 1. Analysis of the indicator diagram shows that the indicators and parameters of the combustion process are as follows: maximum gas pressure of $18.4 \mathrm{MPa}$, the maximum rate of rise of the pressure of $0.38 \mathrm{MPa} / \mathrm{deg}$., the maximum cycle temperature is $1850 \mathrm{~K}$, the start of combustion timing angle of $5 \mathrm{deg}$. before TDC, process time combustion $135 \mathrm{deg}$, and maximum speed fuel burn $0.022 \mathrm{deg}^{-1}$.

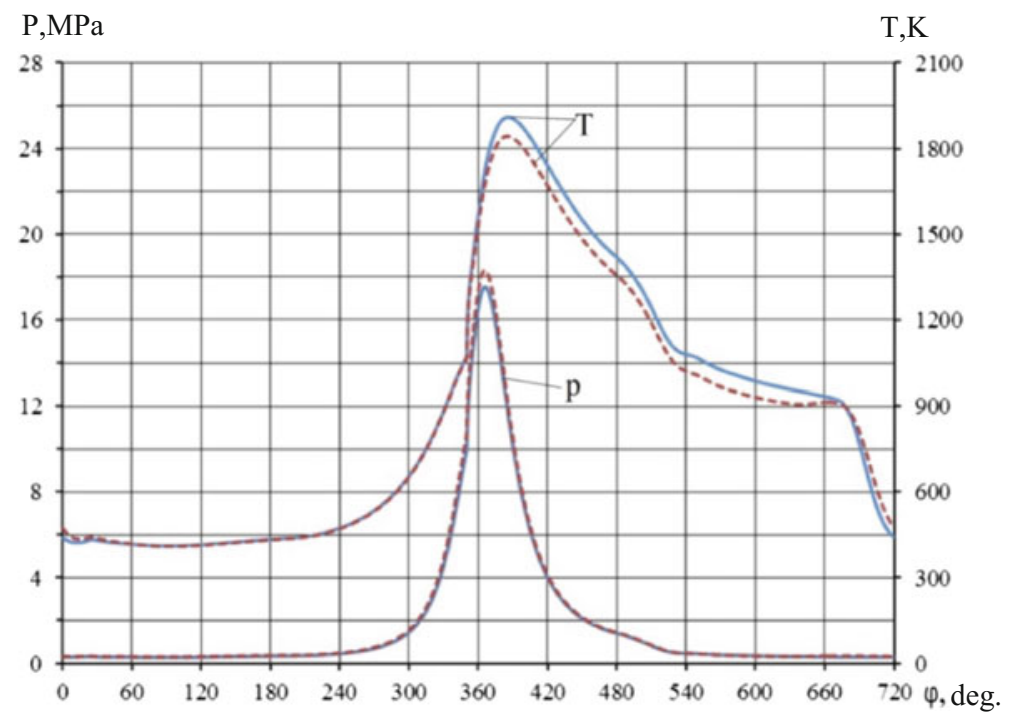

Fig. 1 The indicator diagram of the pressure $\mathrm{P}$ and the temperature $\mathrm{T}$ of gases in the cylinder of the diesel-single-stage supercharging and two-stage supercharging 
Using computer modeling we determined and optimized the following:

- the basic processes of the operating cycle (fuel supply, mixture formation, combustion) and parameters of heat transfer, based on mathematical models of the fuel jet mixing, chemical kinetics, and combustion of fuel nonreacting turbulent gas flow in the combustion chamber with the determination of temperature fields of the combustion chamber surfaces by the finite element method;

- the combustion chamber configuration, based on a mathematical model of gas dynamics reacting turbulent two-phase flow in a three-dimensional setting with a simultaneous selection of the boost parameters, design injector nozzle, and fuel law;

- geometry inlet cylinder head channels, based on a mathematical model of the dynamics nonreacting turbulent gas flow with high Mach numbers in the three-dimensional setting and minimization of areas with the greatest dissipation of turbulent kinetic energy;

- gas distribution phases, based on mathematical models of mass and energy balances of gas in the combustion chamber, intake and exhaust manifolds, one-dimensional flow in the channels of the gas path and submodels of elements of the turbocharged system and charge air;

- boost parameters and characteristics of aggregates with intercooling using a synthesis of operating cycle of diesel;

- dynamics and lubrication of a complex loaded tribosystem with reciprocating and rotational movements of the elements, solution of the boundary conditions for hydrodynamic pressure using multigrid algorithms for bearings with complex geometry of the lubricating layer, taking into account the lubricant sources on the friction surfaces, micro- and macrogeometry, non-Newtonian behavior of the lubricants [10, pp. 22-221; 13, pp. 46-47], and the solution of multi-criteria optimization problems;

- the effect of misalignment of bearings and crankshaft journals, the elastic properties of the crankcase, and crankshaft bearing on the characteristics of the diesel;

- thermal and mechanical loading, the stress-strain state of the cylinder head and crankcase of a diesel engine on the basis of modeling of heat transfer processes in the solid, liquid, and gaseous systems under consideration.

The implementation activities included optimization of the mix parameters characteristics of the gas-turbine supercharging and fuel injection advance angle and reducing the length and increasing the fuel injection pressure. This provides the required fuel efficiency at a high specific power of diesel.

The dynamics of the piston on the lubricating layer in the cylinder of the engine are largely dependent on the profile of the skirt of the piston. The main hydromechanical characteristics (HMC) of the "piston-cylinder" tribosystem are $h_{\min }(\tau)$ - instantaneous values of the minimum oil film thickness; $p_{\max }(\tau)$-instantaneous values of the maximal hydrodynamic pressure; $h_{\min }^{*}$ - average value of $h_{\min }(\tau) ; p_{\max }^{*}$ - average value of $p_{\max }(\tau) ; N(\tau)$ and $N^{*}$-instantaneous and average 
power loss of friction; $Q^{*}$ - the average flow rate of oil in the direction of the combustion chamber; and $T_{e f f}^{*}$ - the average effective temperature of the lubricating layer. To assess the influence of the design parameters on the HMC of the interface "piston-cylinder" of diesel we performed parametric studies for the maximum torque mode.

In accordance with the calculation method given in [3, p. 249; 4, p. 519] we define the profiles of piston skirt in cold and hot conditions, and a profile was built up in the form of a parabola approximation (Fig. 2).

Table presents the results of calculation of the HMC of the "piston-cylinder" tribosystem for initial and recommended interface design before and after optimization. Additionally, we analyzed a non-symmetrical design of the skirt of the piston (see Table 1). It is clear from these results that the optimization of the geometric parameters of the original design improves HMC by $7 \%$.

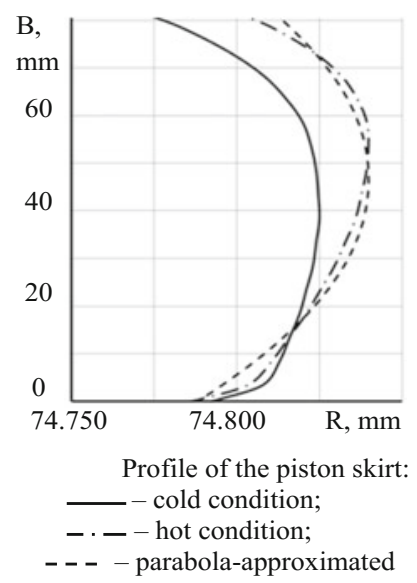

Fig. 2 Profiles of the piston skirt

Table 1 The results of calculation of the HMC of the "piston-cylinder" tribosystem for initial and recommended interface design before and after optimization

\begin{tabular}{l|l|l|l|l|l|l}
\hline Interface design & $\begin{array}{l}N^{*}, \\
\mathrm{~W}\end{array}$ & $\begin{array}{l}Q^{*}, \\
\mathrm{~cm}^{3} / \mathrm{s}\end{array}$ & $\begin{array}{l}\inf h_{\min }, \\
\mu \mathrm{m}\end{array}$ & $\begin{array}{l}h_{\min }^{*}, \\
\mu \mathrm{m}\end{array}$ & $\begin{array}{l}\sup p_{\max }, \\
\mathrm{MPa}\end{array}$ & $\begin{array}{l}p_{\max }^{*}, \\
\mathrm{MPa}\end{array}$ \\
\hline Initial & 463.96 & 76.48 & 36.13 & 124.68 & 5.533 & 1.293 \\
\hline $\begin{array}{l}\text { Optimized with } \\
\text { symmetrical skirt }\end{array}$ & 455.89 & 69.90 & 21.46 & 127.65 & 5.966 & 1.364 \\
$\begin{array}{l}\text { Optimized with } \\
\text { non-symmetrical skirt }\end{array}$ & 450.23 & 68.88 & 36.41 & 129.65 & 5.690 & 1.277 \\
\hline
\end{tabular}




\section{Discussion}

The results given above can help to develop integrated technologies with the following features:

- optimization of the parameters of units of boost at a mass flow of air to $1 \mathrm{~kg} / \mathrm{s}$ and a high degree of pressure increase with deep intercooling according to the criteria of fuel efficiency and thermomechanical loading of the diesel;

- surface profiling of the undivided combustion chamber and a piston skirt forming a bimetallic composite piston, with longitudinal contours of inlet and exhaust channels in the cylinder head to improve gas exchange in the cylinder;

- optimization of the fuel accumulating injection system for the fuel pressure to $200 \mathrm{MPa}$, and cyclic feed to $0.4 \mathrm{~g}$ per cycle;

- improved elements and cooling structure for reducing heat transfer to the coolant;

- improved reliability of the diesel, taking into account the high thermal mechanical loading, providing fluid friction mode in the basic tribounits.

The practical significance of the study is to implement an integrated approach to designing energy-efficient forced diesel on the basis of a differentiated analysis of the functioning of its basic mechanisms and systems. Suggested recommendations were checked using the new motorless bench [7, p. 2-3]. The original design of the bench allows us to register the development of fuel torches at up to 40.000 frames per second (Fig. 3) and can be recommended for the study of the different fuel systems.

Motor testing of diesel on the motor bench HORIBA-SCHENCK DT-2100-1 confirmed the results of the preliminary analysis of the effectiveness of implemented measures to improve the operating cycle. Suggested a new technical solution in the design of diesel engines can be recommended for the practical design of forced diesel engines based on existing and developed technologies for their practical implementation.

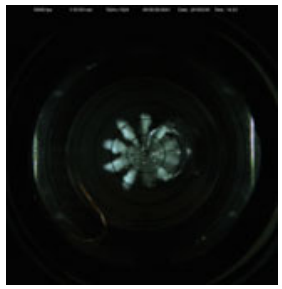

$0,6 \mathrm{Mc}$

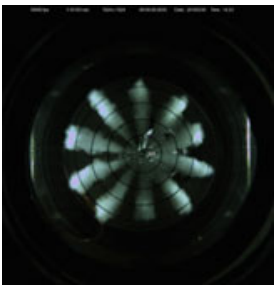

$1,2 \mathrm{Mc}$

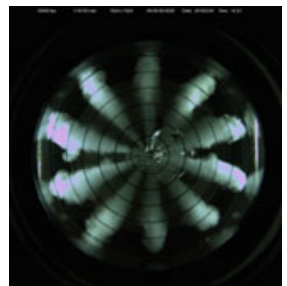

$1,8 \mathrm{Mc}$

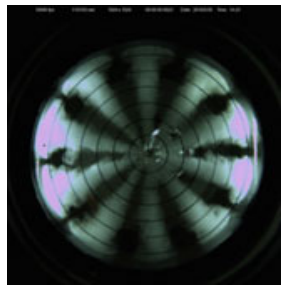

$2,4 \mathrm{Mc}$

Fig. 3 The development of fuel torches in a constant volume chamber (sprayer $10 \times 0.27 \mathrm{~mm}$; $\mathrm{p}_{\text {t.p. }}=165 \mathrm{MPa} ; \tau_{\text {y.inj. }}=1.5 \mathrm{~ms}$ ) 
Comparison of the results of the study with the results of similar work indicates that the achievement of a given level of diesel by competitor companies is provided at a substantially greater weight and size with a similar level of fuel efficiency.

\section{Conclusions}

A brief analysis of current trends in the development of diesel engines and theoretical aspects of their implementation show that reserves are not exhausted in this direction. It is necessary to combine known and new methods and means of improving the operating cycle with advanced solutions in the design of the basic mechanisms and systems. As a result, we were able to achieve the required technical level. As a result, we were able to achieve the required technical level of the designed diesel.

Acknowledgements This research was carried out with the financial support of the Ministry of Education and Science of the Russian Federation for the implementation of applied research studies, lot 2014-14-579-0109. Agreement (contract) no. 14.577.21.0102, September 16, 2014. Unique identifier of Applied Scientific Research Project RFMEFI57714X0102.

\section{References}

1. Dober, G., Guerrassi, N., Karimi, K.: Mixture preparation and combustion analysis, a key activity for future trends in diesel fuel injection equipment. SIA Diesel Powertrain International Conference, Rouen, p. 10. http://delphi.com/images/news/2012/DelphiCombustion-Technical-PaperSIA-Diesel-Rouen-2012.pdf/ (June 2012). 10p

2. Eagle, W.E., Morris, S.B., Wooldridge, M.S.: High-speed imaging of transient diesel spray behavior during high pressure injection of a multi-hole fuel injector. Fuel 116, 299-309 (2014)

3. Goritskiy, Y., Ismailova, Y., Gavrilov, K., Rozhdestvensky, Y., Doikin, A.: A Numerical Model for Mechanical Interaction of Rough Surfaces of the "Piston-Cylinder Liner" Tribosystem. FME Trans. 43, 249-253 (2015)

4. Goritskiy, Y., Gavrilov, K., Rozhdestvensky, Y., Doikin, A.L: A numerical model of mechanical interaction between rough surfaces of tribosystem of the high forced diesel engine. Procedia Engi. 129, 518-525 (2015)

5. Kamaltdinov, V.G., Lysov, I.O., Nikiforov, S.S.: Diesel Engine operating cycle optimization with simulation of combustion process by double-Wiebe function. Procedia Eng. 129, 873-878 (2015)

6. Kamaltdinov, V.G., Markov, V.A., Lysov, I.O.: Modeling the combustion process of a powerful diesel engine. Procedia Eng. 129, 488-494 (2015)

7. Kamaltdinov, V.G., Rozhdestvensky, Y.V., Lysov, I.O., Popov, A.Y., Nikiforov, S.S.: Experimental investigations of the effects of electric control impulse on injection characteristics of common rail type injector. Indian J. Sci. Technol. 9(42) (2016). doi: 10.17485/ijst/ 2016/v9i42/104225. 4p 
8. Lazarev, E.A.: Basic principles, methods and means of improving the efficiency of the combustion process to improve the technical level of tractor diesel: a monograph. Publishing Center of SUSU, Chelyabinsk (2010). 289p

9. Mozer, Franc K.: Trends and solutions in the development of commercial diesel. Proceedings of the International Scientific Conference "Turbocharging of automobile and tractor engines", p. 6-12, Protvino, 24-25 June 2009

10. Mukchortov, I., Zadorozhnaya, E., Levanov, I., Pochkaylo, K.: The influence of poly-molecular adsorption on the rheological behaviour of lubricating oil in a thin layer. FME Trans. 43, 218-222 (2015)

11. Postrioti, L., Buitoni, G., Pesce, F., Ciaravino, C.: Zeuch method-based injection rate analysis of a common-rail system operated with advanced injection strategies. Fuel. 128, 188-198 (2014)

12. Lu, Y., Zhang, X., Xiang, P., Dong, D.: Analysis of thermal temperature fields and thermal stress under steady temperature field of diesel engine piston. Appl. Therm. Eng. 113, 796-812 (2015)

13. Zadorozhnaya, E.A.: Solving a thermohydrodynamic lubrication problem for complex loaded sliding bearings with allowance for rheological behavior of lubricating fluid. J. Machinery Manufacture Reliability 44(1), 46-56 (2015)

Open Access This chapter is licensed under the terms of the Creative Commons Attribution 4.0 International License (http://creativecommons.org/licenses/by/4.0/), which permits use, sharing, adaptation, distribution and reproduction in any medium or format, as long as you give appropriate credit to the original author(s) and the source, provide a link to the Creative Commons license and indicate if changes were made.

The images or other third party material in this chapter are included in the chapter's Creative Commons license, unless indicated otherwise in a credit line to the material. If material is not included in the chapter's Creative Commons license and your intended use is not permitted by statutory regulation or exceeds the permitted use, you will need to obtain permission directly from the copyright holder.

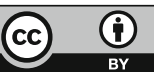

